\title{
Plasma Membrane Potential of Candida albicans Measured by Di-4-ANEPPS Fluorescence Depends on Growth Phase and Regulatory Factors
}

\author{
Jakub Suchodolski and Anna Krasowska * \\ Department of Biotransformation, Faculty of Biotechnology, University of Wroclaw, 50-383 Wrocław, Poland; \\ jakub.suchodolski@uwr.edu.pl \\ * Correspondence: anna.krasowska@uwr.edu.pl
}

Received: 9 March 2019; Accepted: 22 April 2019; Published: 24 April 2019

\begin{abstract}
The potential of the plasma membrane $(\Delta \psi)$ regulates the electrochemical potential between the outer and inner sides of cell membranes. The opportunistic fungal pathogen, Candida albicans, regulates the membrane potential in response to environmental conditions, as well as the physiological state of the cell. Here we demonstrate a new method for detection of cell membrane depolarization/permeabilization in C. albicans using the potentiometric zwitterionic dye di-4-ANEPPS. Di-4-ANEPPS measures the changes in the cell $\Delta \psi$ depending on the phases of growth and external factors regulating $\Delta \psi$, such as potassium or calcium chlorides, amiodarone or DM-11 (inhibitor of $\mathrm{H}^{+}$-ATPase). We also demonstrated that di-4-ANEPPS is a good tool for fast measurement of the influence of amphipathic compounds on $\Delta \psi$.
\end{abstract}

Keywords: Candida albicans; plasma membrane potential; membrane polarization; di-4-ANEPPS; detergents

\section{Introduction}

Though the plasma membrane potential $(\Delta \psi)$ is an electrochemical potential difference between extracellular and intracellular compartments in all living cells, the mechanisms maintaining $\Delta \psi$ differ between cell types [1]. $\Delta \psi$ acts as an indicator of the physiological status of the cell; for example, depolarization of the cell membrane in lymphocytes prevents cell proliferation [2]. The influence of the value of $\Delta \psi$ on the lipid lateral localization in the plasma membrane of the yeast Saccharomyces cerevisiae is another example that highlights the importance of the $\Delta \psi$ in cell biology [3].

Candida albicans is a microorganism of human microflora (skin, as well as urinary and gastrointestinal tracts) and the most common cause of opportunistic fungal infections of immunocompromised patients [4]. The value of C. albicans $\Delta \psi$ is $\sim-120 \mathrm{mV}$ and is comparable to that of pathogenic bacteria, which ranges from $\sim-130 \mathrm{mV}$ to $\sim-150 \mathrm{mV}[5,6]$. Unlike in C. albicans, the value of $\Delta \psi$ of non-pathogenic $S$. cerevisiae is $\sim-71 \mathrm{mV}$ and is comparable to the potential of mammalian cells, which is $\sim 90 \mathrm{mV}[5,6]$.

Highly desirable activities of antifungal compounds include binding to ergosterol and subsequent permeabilization of the cell membrane $[7,8]$. The loss of cell membrane integrity due to the action of antifungal drugs causes plasma membrane depolarization [9].

Two types of fluorescent probes are commonly used for measurements of C. albicans plasma membrane polarity: slow response potential-sensitive cationic carbocyanines (Dil, DiS and DiO) and anionic bis-barbituric acid oxonols (DiBAC) [10-13].

Carbocyanines accumulate in hyperpolarized membranes, while bis-oxonol dyes enter depolarized cells $[13,14]$. Binding to the cell by both groups of dyes results in a red shift of the fluorescence 
spectrum while a blue shift of fluorescence spectrum is observed when probes are not bound [12,15]. Accumulation of the cationic and anionic dyes in the plasma membrane and changes of $\Delta \psi$ caused by interfering factors require constant monitoring of the time course of the fluorescence spectrum shifts. Additionally, carbocyanines are substrates for C. albicans drug ATP-binding cassette (ABC) transporters (Cdr1 and Cdr2) and are used to measure the activity of these pumps in real time [15]. However, Cadek et al. [16] found that the excretion of carbocyanines by ABC transporters could interfere with the proper measurement of cell membrane potential.

Potentiometric zwitterionic aminonaphthylethenylpyridinium (ANEP) dyes (di-4-ANEPPS and di-8-ANEPPS) were previously used to map the membrane potential along neurons and muscle fibers [16-18]. Both probes reduce the excitation fluorescence intensity at $\sim 440 \mathrm{~nm}$ and increase it at $\sim 530 \mathrm{~nm}$ in response to membrane hyperpolarization $[19,20]$. In addition, after excitation in the range of $470 \mathrm{~nm}$ to $490 \mathrm{~nm}$, ANEP dyes cause a blue or red fluorescence shift during depolarization or hyperpolarization of membranes, respectively [21-23]. Di-4-ANEPPS was also used for measuring membrane potential in S. cerevisiae. The use of this dye in these walled cells showed its lower stability, but faster response, in comparison to previously used cationic and anionic dyes [24].

In this study, we report a new application of monitoring di-4-ANEPPS fluorescence spectral shift in Candida albicans' $\Delta \psi$ measurement. We developed a straightforward and reliable assay in monitoring de-/hyperpolarization as a result of ion homeostasis disturbance and after treatment with amphipathic compounds, which may provide a better understanding of the physiology of C. albicans.

\section{Materials and Methods}

\subsection{Chemicals, Strains and Growth Conditions}

All chemicals and reagents used in this study were purchased from the following sources: 3,3'-Dipropylthiacarbocyanine iodide ( diS- $_{3}(3)$ ), sodium dodecyl sulfate (SDS), benzalkonium chloride (BAC), Triton X-100 (Sigma-Aldrich; Poznań, Poland); D-glucose, bacteriological agar, propidium iodide (PI) (manufacturer: Bioshop, distributor: Lab Empire; Rzeszów, Poland); peptone, yeast extract (YE) (manufacturer: BD; distributor: Diag-med; Warszawa, Poland); potassium chloride (KCl) (Chempur; Piekary Ślaskie, Poland); calcium chloride $\left(\mathrm{CaCl}_{2}\right)(\mathrm{POCH}$; Gliwice, Poland); pyridinium, 4-(2-(6-(dibutylamino)-2-naphthalenyl)ethenyl)-1-(3-sulfopropyl), hydroxide inner salt (di-4-ANEPPS) (Thermo Fisher; Warszawa, Poland); 2-dodecanoyloxyethyl-dimethylammonum chloride (DM-11) was a gift from Dr. Łuczyński (Wroclaw, Poland).

C. albicans strain CAF2-1 (genotype: ura3 $\triangle:$ imm434/URA3) was a kind gift from prof. D. Sanglard (Lausanne, Switzerland) [25]. It was routinely grown at $28{ }^{\circ} \mathrm{C}$ on YPD medium ( $2 \%$ glucose, $1 \%$ peptone, $1 \%$ YE) in a shaking incubator (120 rpm). Agar in a final concentration of $2 \%$ was used for medium solidification.

To determine growth phases, CAF2-1 was grown in $20 \mathrm{~mL}$ of YPD medium for $24 \mathrm{~h}$ at $28^{\circ} \mathrm{C}$ with shaking (120 rpm). Every two hours, the $\mathrm{A}_{600}$ measurements were performed using a Hach Odyssey $\mathrm{DR} / 2500$ spectrophotometer in three independent repetitions.

For specific experiments, CAF2-1 cells were grown until they reached either early $(8 \mathrm{~h})$ or late (14 h) logarithmic phase.

\section{2. $\mathrm{DiS}_{-} \mathrm{C}_{3}(3)$ Assay}

The fluorescence assay of $\Delta \psi$ was performed in the early and late logarithmic phase of $C$. albicans growth as described previously [26]. $\Delta \psi$ measurements using de- and hyperpolarizing compounds (200 mM KCl, $50 \mu \mathrm{M}$ DM-11; 25 mM CaCl $2,2 \mu \mathrm{M}$ Amiodarone, respectively) and di-4-ANEPPS (final conc. $=3 \times 10^{-6} \mathrm{M}$ ) were performed in the early phase of growth. All reagents were prepared shortly before fluorescence measurements and added at $\mathrm{t}=0 \mathrm{~min}$ (de- and hyperpolarizing compounds) or at $\mathrm{t}=60 \mathrm{~min}$ (di-4-ANEPPS). 


\subsection{Di-4-ANEPPS Assay}

Detection of $\Delta \psi$ by di-4-ANEPPS was performed by labelling $3 \mathrm{~mL}$ of $C$. albicans cell suspensions $\left(\mathrm{A}_{600}=0.1\right)$ in citrate phosphate $(\mathrm{CP})$ buffer $(\mathrm{pH}$ 6.0). The final concentration of di-4-ANEPPS probe was $3 \times 10^{-6} \mathrm{M}$. Samples were incubated for $30 \mathrm{~min}$ at room temperature (RT). The growth-dependent membrane potential was measured both in the early and late logarithmic phase of $C$. albicans growth. Membrane potential measurements using de- and hyperpolarizing compounds $(200 \mathrm{mM} \mathrm{KCl}, 50 \mu \mathrm{M}$ DM-11; $25 \mathrm{mMCaCl}_{2}, 2 \mu \mathrm{M}$ Amiodarone respectively) were performed only in the early phase of growth because of physiological depolarization of plasma membrane in late log phase cells. $\mathrm{KCl}, \mathrm{DM}-11, \mathrm{CaCl}_{2}$, Amiodarone were added immediately after incubation of cells with di-4-ANEPPS. In all experiments, di-4-ANEPPS was excited at $488 \mathrm{~nm}$ (Ex slit $=10 \mathrm{~nm}$ ) and fluorescence spectra at 520-720 nm (Em slit = $2.5 \mathrm{~nm})($ PMT voltage $=700 \mathrm{~V})$ were recorded using fluorescence spectrophotometer (HITACHI F-4500) equipped with a xenon lamp. Each experiment was performed in three independent replications and each probe was excited three times. Fluorescence spectra from corresponding experiments were averaged and normalized (value 1 for maximum emission intensity in each case) for comparison of fluorescence maxima shifts.

\subsection{Toxicity of di-4-ANEPPS}

C. albicans suspensions were treated as described in Section 2.3 ( $\mathrm{CP}$ buffer; $\mathrm{A}_{600}=0.1 ; 3 \times 10^{-6} \mathrm{M}$ di-4-ANEPPS; $30 \mathrm{~min}$ ), washed with $\mathrm{CP}$, and resuspended in $\mathrm{CP}\left(10^{0}\right)$. Suspensions were serially diluted up to $10^{-3}$, then $2 \mu \mathrm{L}$ were spotted onto YPD agar and cultured for $48 \mathrm{~h}$ at $28^{\circ} \mathrm{C}$. Afterwards, the plates were photographed using FastGene ${ }^{\circledR}$ B/G GelPic imaging box (Nippon Genetics, Dueren, Germany).

\subsection{Influence of Detergents on $\Delta \psi$}

The impact of SDS $(0-320 \mu \mathrm{g} / \mathrm{mL})$, BAC $(0-320 \mu \mathrm{g} / \mathrm{mL})$ and Triton X-100 $(0-320 \mu \mathrm{g} / \mathrm{mL})$ on $\Delta \psi$ was evaluated as described in Section 2.3, with modifications. Fluorescence spectra of di-4-ANEPPS $\left(3 \times 10^{-6} \mathrm{M}\right)$ solution in $\mathrm{CP}$ buffer $(\mathrm{pH}$ 6.0) were collected after $30 \mathrm{~min}$ incubation in the presence of detergents. Because an interaction between the fluorescent probe and detergents was identified, early $\log$ phase $C$. albicans cells were pretreated with detergents for $30 \mathrm{~min}$ at RT, washed three times with $\mathrm{CP}$ buffer ( $\mathrm{pH}$ 6.0), and labelled with di-4-ANEPPS for $30 \mathrm{~min}$. Fluorescence measurements were performed as described above. For data analysis, the red-blue signal ratio (R-B ratio) was calculated by dividing the sum of fluorescence intensity (IF) between 580 and $620 \mathrm{~nm}$ by the sum of IF between 540 and $580 \mathrm{~nm}$ as shown in the formula below.

$$
R B \text { ratio }=\frac{\sum_{i=580 \mathrm{~nm}}^{620 \mathrm{~nm}} I F i}{\sum_{i=540 \mathrm{~nm}}^{580 \mathrm{~mm}} I F i}
$$

Additionally, all results were normalized to the control (value $=1$ for the control experiment without the addition of detergents). In this approach, it was assumed that the fluorescence spectra symmetry had a maximum at $580 \mathrm{~nm}$ (plasma membrane potential of early log phase cells in control conditions); therefore, blue shift (depolarization) and red shift (hyperpolarization) result in an R-B ratio of $<1$ and $>1$, respectively.

\subsection{Propidium Iodide (PI) Staining}

Assessment of plasma membrane permeability was performed as described before [8], with modifications. Briefly, $3 \mathrm{~mL}$ of $C$. albicans cell suspensions $\left(\mathrm{A}_{600}=0.1\right)$ in $\mathrm{CP}$ buffer $(\mathrm{pH} 6.0)$ were mixed with SDS $(0-320 \mu \mathrm{g} / \mathrm{mL})$, BAC $(0-320 \mu \mathrm{g} / \mathrm{mL})$ or Triton X-100 $(0-320 \mu \mathrm{g} / \mathrm{mL})$, incubated for $30 \mathrm{~min}$ at RT, washed three times with $\mathrm{CP}$ buffer, and stained for $5 \mathrm{~min}$ with PI to the final dye concentration of $6 \times 10^{-6} \mathrm{M}$. Next, cell suspensions were washed twice with $\mathrm{CP}$ buffer and observed under a Zeiss Axio Imager A2 microscope equipped with a Zeiss Axiocam 503 mono microscope camera and a Zeiss HBO100 mercury lamp. The percentage of permeabilized cells was evaluated by counting PI 
positive cells out of one hundred cells in three independent repetitions for each experiment. Statistical significance analysis was performed using Student's t-test (binomial, unpaired).

\subsection{Sequences Alignmets}

TOK1 gene and Tok1p sequences from S. cerevisiae S288C strain were obtained from Saccharomyces Genome Database (accession ID: SGD:S000003629) [27]. TOK1 gene and Tok1p sequences from C. albicans SC5314 strain were obtained from Candida Genome Database (accession by systematic name: C4_00670W_A) [28]. Sequences alignments were performed by EMBOSS Needle program [29].

\section{Results and Discussion}

Di-4-ANEPPS dye is widely used in the measurement of the $\Delta \psi$ in tissues [30], but in walled cells it was used only in yeast $S$. cerevisiae [24]. $\mathrm{H}^{+}$-ATPase forms $\Delta \psi$ in both pathogenic $C$. albicans and non-pathogenic S. cerevisiae, but its activity in these two species is different. In contrast to S. cerevisiae, C. albicans up-regulates energy reserve metabolism [31] and has a lower acidification activity of $\mathrm{H}^{+}$-ATPase [32]. Our previous investigations indicated that the $\Delta \psi$ of C. albicans measured by diS- $C_{3}(3)$ dye differs from S. cerevisiae [15]. To expand this observation, we used di-4-ANEPPS to measure C. albicans' $\Delta \psi$ under different conditions and compare this method with the method using $\operatorname{diS}-\mathrm{C}_{3}(3)$.

\subsection{Di-4-ANEPPS and DiS-C $C_{3}(3)$ Measure Cell Depolarization Depending on the Phases of Growth}

First, we compared diS- $C_{3}(3)$ and di-4-ANEPPS in the detection of growth phase-dependent plasma membrane depolarization for C. albicans (Figure 1A,B). Previously, depolarization of S. cerevisiae plasma membrane resulting from decreased $\mathrm{H}^{+}$-ATPase activity in the late exponential phase was observed using diS- $C_{3}(3)[16,33]$. In the case of $C$. albicans, log phase was observed between 8 to $14 \mathrm{~h}$ of growth (Figure 1C). Staining with diS- $\mathrm{C}_{3}(3)$ in the cells was considerably slower in the late log phase ( $\lambda \max =\sim 572 \mathrm{~nm}$ at $40 \mathrm{~min})$ compared to the early phase $(\lambda \max =\sim 577-578 \mathrm{~nm}$ at $28 \mathrm{~min})$ of exponential growth (Figure 1A), which indicates membrane depolarization and is in agreement with our previous studies [15].

In our study, we used the C. albicans CAF2-1 strain, which has both ABC transporters (Cdr1 and Cdr2). DiS- $C_{3}(3)$ is the substrate for $A B C$ transporters and its efflux is observed at $40-50$ min after addition of it to the $S$. cerevisiae cell suspension [16]. In the case of $C$. albicans, an efflux of this dye occurs after 60-70 minutes (Figure 1E, control) [15]. For $\Delta \psi$ measurements, we did not monitor diS- $C_{3}(3)$ fluorescence longer than that to avoid $\mathrm{ABC}$ transporters interference.

We compared the fluorescence spectrum of di-4-ANEPPS bound to plasma membrane of C. albicans cells in early and late exponential phases of growth (Figure 1B). The di-4-ANEPPS emission maximum (EM) was at $\sim 580 \mathrm{~nm}$ for the early exponential phase, whereas in the late exponential cells the EM shifted to $\sim 574 \mathrm{~nm}$, with the spectrum area being noticeably narrowed. Blue-shift of di-4-ANEPPS fluorescence indicates depolarization of the plasma membrane, as previously reported for tissues stained with ANEP dyes [23,34].

In our experiments, di-4-ANEPPS treatment was not toxic in C. albicans (Figure 1D). We conclude that $\Delta \psi$ measurements were not affected by an adverse effect of the dye on C. albicans cells. Additionally, di-4-ANEPPS did not inhibit diS- $\mathrm{C}_{3}(3)$ efflux after addition at $60 \mathrm{~min}$. (Figure 1E). The addition of $\mathrm{ABC}$ transporter substrate during diS- $\mathrm{C}_{3}(3)$ assay results in lower or lack of diS- $\mathrm{C}_{3}(3)$ efflux [15], thus di-4-ANEPPS is not an $A B C$ transporter substrate and $\triangle \psi$ measurements were not affected by the $A B C$ transporters efflux activity. 
A

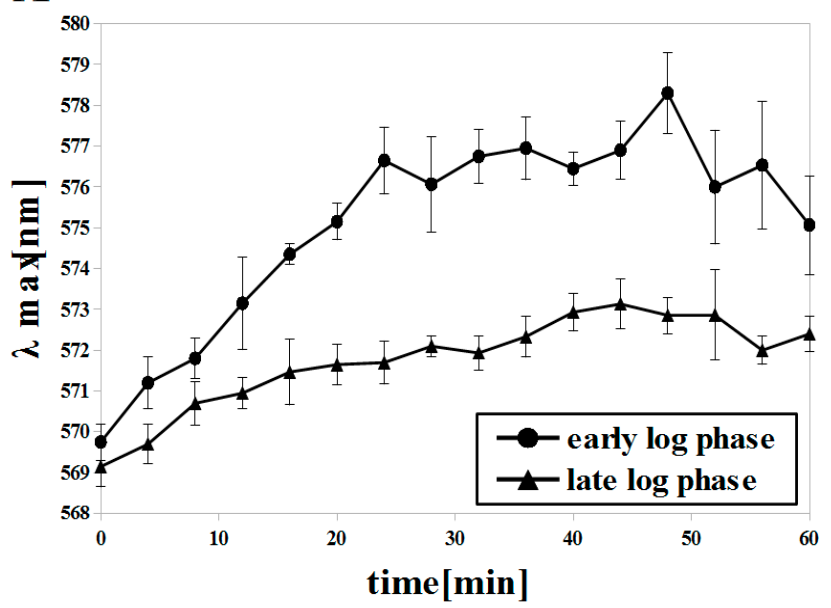

$\mathrm{C}_{30}$

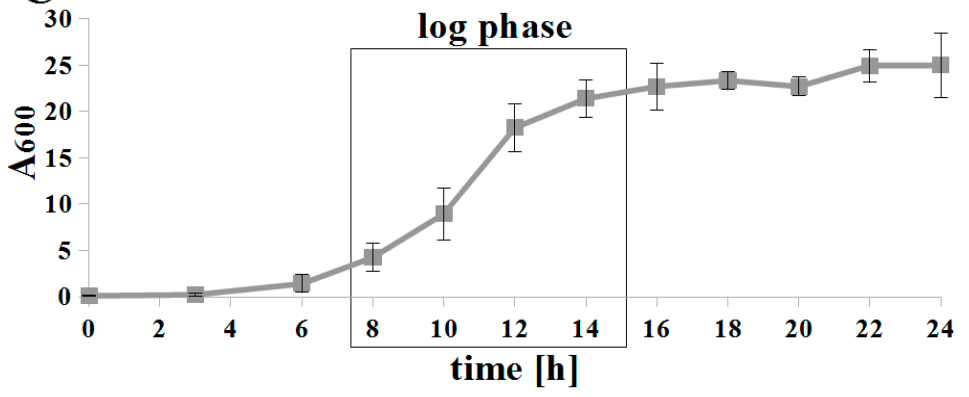

$\underline{\mathbf{B}}$

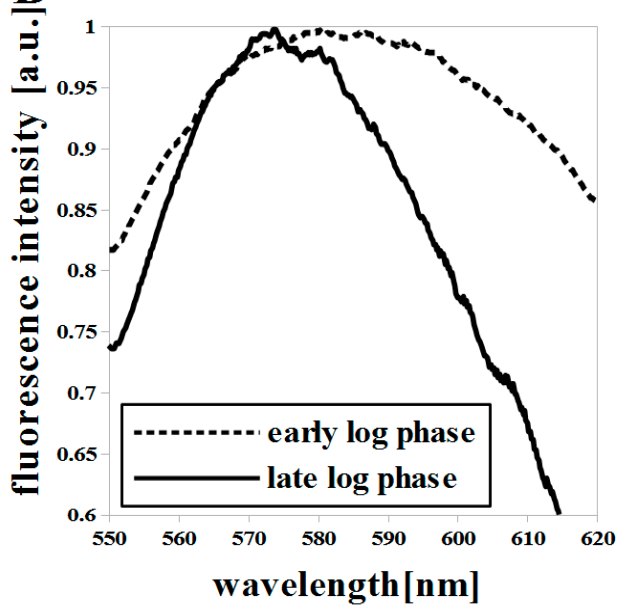

D

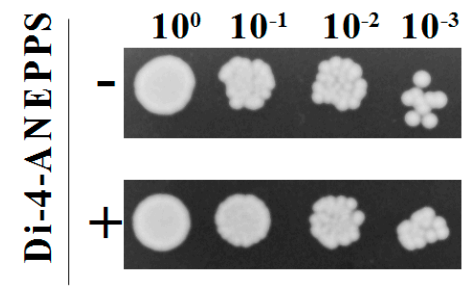

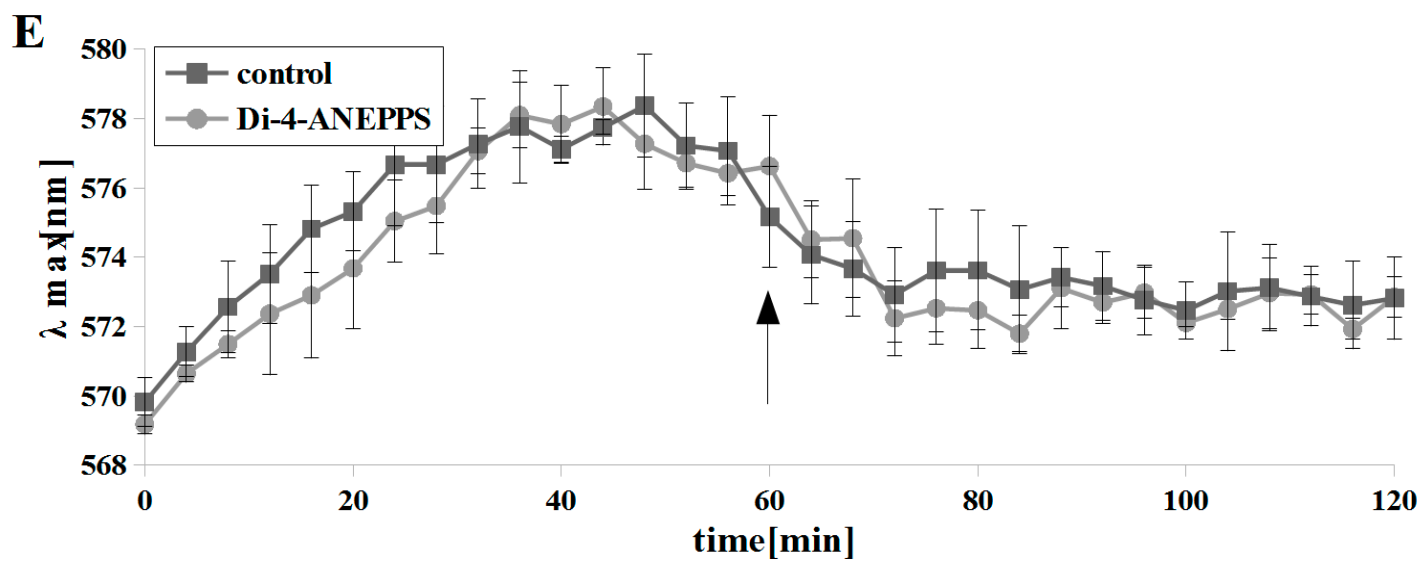

Figure 1. Growth phase-dependent depolarization of $C$. albicans cells measured by: (A) monitoring fluorescence maxima in time by diS- $C_{3}(3)$, means \pm SD $(n=4)$ and $(B)$ fluorescence spectrum shift of di-4-ANEPPS (red-blue signal ratio $(\mathrm{R}-\mathrm{B})$ values $=1.043 \pm 0.011$ and $0.921 \pm 0.002$ for $8 \mathrm{~h}$ and $14 \mathrm{~h}$, respectively), each spectrum is averaged $(n=9)$; $($ C) growth curve of $C$. albicans CAF2-1, strain was grown to $8 \mathrm{~h}$ and $14 \mathrm{~h}$ (early and late $\log$ phases), means $\pm \mathrm{SD}(\mathrm{n}=3)$; $(\mathrm{D})$ di-4-ANEPPS was not toxic towards $C$. albicans CAF2-1; (E) ATP-binding cassettes (ABC) mediated diS- $\mathrm{C}_{3}(3)$ efflux was not inhibited by addition (arrow) of di-4-ANEPPS, means \pm SD $(n=4)$.

\subsection{Di-4-ANEPPS and DiS-C $C_{3}(3)$ Measure Cell Depolarization and Hyperpolarization Induced by External Factors}

In addition to $\mathrm{H}^{+}$-ATPase, other transmembrane transporters form $\Delta \psi$ in pathogenic and non-pathogenic yeast. $\mathrm{K}^{+}$ions are transported to the inside of the C. albicans cells by Trk1p uniporter. The single Trk isoform (CaTrk1p) in C. albicans is nearly $60 \%$ homologous in four transmembrane motifs to both isoforms of Trkp in S. cerevisiae; this is expected to reflect quantitatively similar functions of these transporters [35]. C. albicans needs a highly efficient $\mathrm{K}^{+}$uptake system because of low concentration 
of potassium in the niches of the host organism [36]. The accumulation of potassium ions inside the cell depolarizes the plasma membrane, as demonstrated in S. cerevisiae by Gaskova et al. [37] using diS- $C_{3}(3)$ dye. We used diS- $C_{3}(3)$ and di-4-ANEPPS dyes to measure the $C$. albicans $\Delta \psi$ after $\mathrm{KCl}$ application (Figure 2A,B). A blue shift of $\lambda \max$ (di-4-ANEPPS; EM: $575 \mathrm{~nm}$ ) and fluorescence intensity kinetics $\left(\mathrm{diS}_{-} \mathrm{C}_{3}(3) ; \lambda \max =\sim 575-576 \mathrm{~nm}\right.$ at $50 \mathrm{~min}$ ) were observed (Figure 2A,B), which indicate depolarization of the membrane.
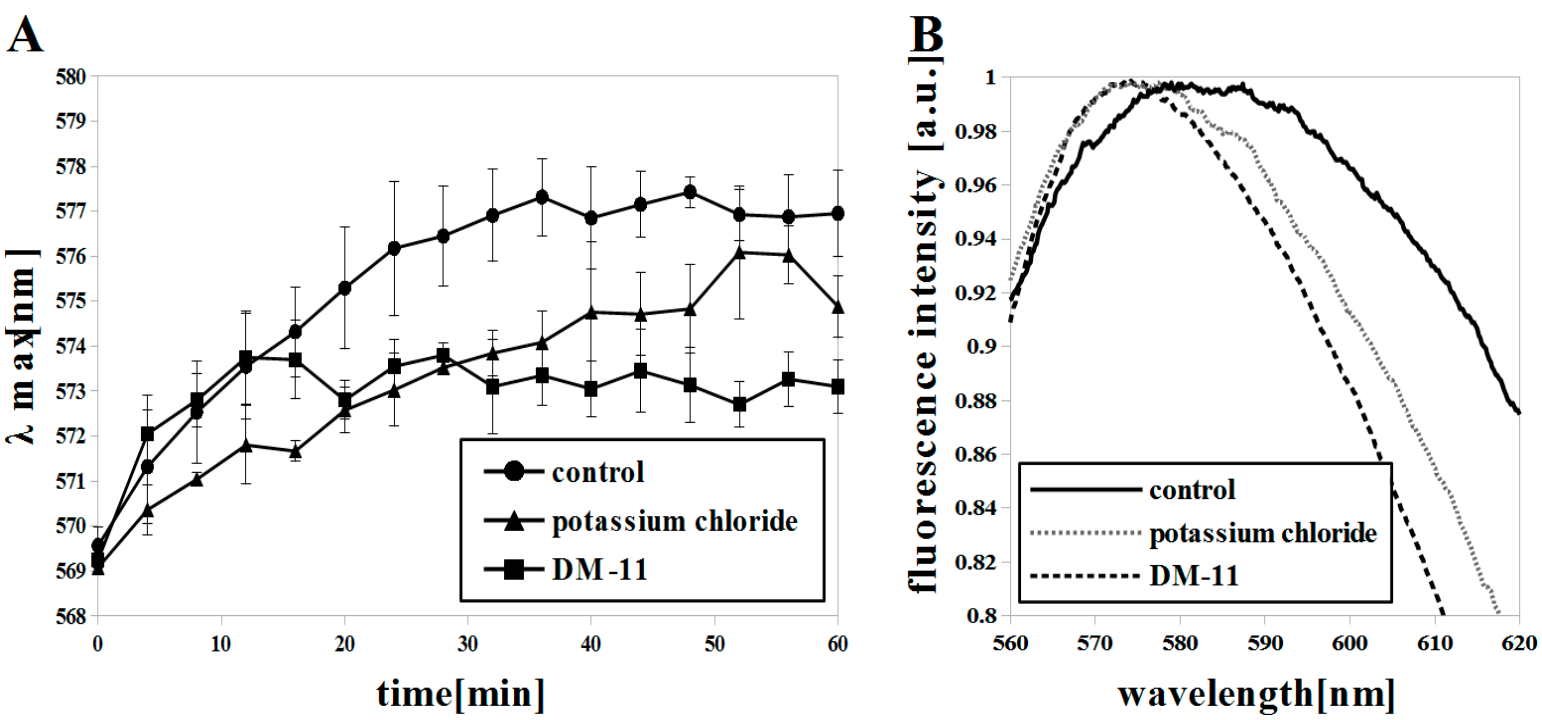

Figure 2. Plasma membrane potential $(\Delta \psi)$ reduction and membrane depolarization in C. albicans induced by $\mathrm{KCl}(200 \mathrm{mM})$ and DM-11 $(50 \mu \mathrm{M})$ in early log phase $(8 \mathrm{~h})$ shown by: (A) diS- $\mathrm{C}_{3}(3)$, means $\pm \mathrm{SD}(\mathrm{n}=4)$ and $(\mathrm{B})$ di-4-ANEPPS (R-B values $=1.040 \pm 0.025,0.991 \pm 0.002$ and $0.978 \pm 0.010$ for control, $\mathrm{KCl}, \mathrm{DM}-11$, respectively), each spectrum is averaged $(\mathrm{n}=9)$.

Among transmembrane transporters that contribute to $\Delta \psi$ are regulators of intracellular potassium concentrations, such as the Tok1 channel [38]. Tok1p is a potassium specific channel that releases $\mathrm{K}^{+}$ from the cell and thus regenerates $\Delta \psi$ [39]. Deletion of the TOK1 gene results in the depolarization of plasma membrane, and conversely, its overexpression leads to hyperpolarization of the yeast plasma membrane $[40,41]$. In our investigations, the $C$. albicans $\Delta \psi$ was measured with diS- $C_{3}(3)$ dye in real time for $60 \mathrm{~min}$. The $\Delta \psi$ grew more slowly after using $\mathrm{KCl}$ ( $\lambda$ max at $\sim 50 \mathrm{~min}$ ) than in cells not treated with $\mathrm{KCl}$ ( $\lambda \max$ at $\sim 30 \mathrm{~min}$ ), but it finally achieved similar $\lambda \max$ values (Figure $2 \mathrm{~A}$ ). By using the di-4-ANEPPS dye and observing the blue shift of fluorescence intensity (control EM: $582 \mathrm{~nm}$; KCl treated EM: $576 \mathrm{~nm}$ ) we have shown that the plasma membrane of $C$. albicans' cells is depolarized (Figure 2B). However, the intensity of this depolarization is lower than after treatment of cells with DM-11 (EM: $574 \mathrm{~nm}$ ), which is a known $\mathrm{H}^{+}$-ATPase inhibitor in yeast (Figure 2B) [42,43]. We observed reduced staining of cells with diS- $C_{3}(3)$ after $10 \mathrm{~min}$. incubation with DM-11 and no $\Delta \psi$ recovery (Figure 2). DM-11 is a lysosomotropic agent whose deprotonated form penetrates membranes and protonated form accumulates in acidic yeast compartments (e.g., vacuoles). If this compound is used in high concentrations it can cause membrane disruption [44]. Zahumensky et al. [45] have observed the increase of Tok1p activity in S. cerevisiae cells treated with DM-11 and a gradually more extensive Tok1 channel activity with deeper depolarization of the membrane.

Our results indicate a weaker role of Tok1p in $\Delta \psi$ recovery after treatment of cells with DM-11 and deeper membrane depolarization than when using $\mathrm{KCl}$ (Figure 2A,B). According to the sequence alignment (Section 2.7), the CaTOK1 gene sequence is identical to the ScTOK1 gene in $48.6 \%$ and CaTok1p with ScTok1p in 31.4\%, which can indicate partially different functions of these transporters. The staining of $C$. albicans strains by diS- $C_{3}(3)$ is approximately twice as slow as that of $S$. cerevisiae [15]. The reason for this difference in the rate of staining could be a lower $\Delta \psi$ in C. albicans cells relative to 
S. cerevisiae cells. Probably for these reasons, the $\Delta \psi$ reduction and membrane depolarization following the blockage of $\mathrm{H}^{+}$-ATPase by DM-11 in C. albicans are not recovered by Tok1p activity.

Calcium channels in S. cerevisiae have been identified as high-affinity and low-affinity calcium uptake systems (HACS and LACS). The voltage-gated Cch1p [46] and the stretch-activated Mid1p [47] form a complex that defines the HACS, whereas Fig1p is a component of LACS [48]. The homologs of these genes in C. albicans were found by Brandt et al. [49]. CaCCH1 has a $38.4 \%$ identity to its S. cerevisiae homolog while the CaMID1 gene sequence had 36.9\% identity to ScMID1 [49]. In S. cerevisiae, HACS is activated by low $\mathrm{Ca}^{2+}$, whereas LACS activity was only revealed under conditions when HACS was inhibited by rich media and its affinity for $\mathrm{Ca}^{2+}$ is 16-fold lower [50]. Brandt et al. [49] observed a similar dependence in C. albicans. The perturbation of calcium homeostasis by the influx of $\mathrm{Ca}^{2+}$ into C. albicans cells leads to their death. This finding has allowed amiodarone (AMD) to be used as an antifungal drug. Maresova et al. [41] and Pena et al. [51] suggested that AMD elicits plasma membrane hyperpolarization by inducing $\mathrm{K}^{+}$efflux from the cells followed by depolarization resulting in the $\mathrm{Ca}^{2+}$ influx and loss of cell viability.

We used a high concentration of $\mathrm{CaCl}_{2}(25 \mathrm{mM})$ to force the cells to take up $\mathrm{Ca}^{2+}$ through the LACS system and to induce membrane hyperpolarization. The measurements with diS- $C_{3}(3)$ indicated a $\Delta \psi$ increase $(\lambda \max =\sim 578-9$ at $\sim 40 \mathrm{~min}$ ) almost with the same intensity as in the case of cells with a low concentration of $\mathrm{CaCl}_{2}(\lambda \max =\sim 577-8$ at $\sim 40 \mathrm{~min}$ ) (Figure $3 \mathrm{~A}$ ). Di-4-ANEPPS fluorescence showed only a slight red shift in cells with $25 \mathrm{mM} \mathrm{CaCl}_{2}$ (control EM: $575 \mathrm{~nm} ; \mathrm{CaCl}_{2}$ treated EM: $577 \mathrm{~nm}$ ) (Figure 3B). Callahora et al. [52] pointed out that agents that did not produce an efflux of $\mathrm{K}^{+}$also did not produce increased $\mathrm{Ca}^{2+}$ uptake, and those that produced $\mathrm{K}^{+}$efflux increased $\mathrm{Ca}^{2+}$ uptake. Transport across the plasma membrane in C. albicans cells appears to be reversible. A slight red shift of the di-4-ANEPPS fluorescence indicating low hyperpolarization in our $\mathrm{CaCl}_{2}$ studies may be due to compensation of the negative charge on the outside of membrane by $\mathrm{K}^{+}$efflux from the cells. On the other hand, when we used AMD we observed a fast $\Delta \psi$ build up ( $\lambda$ max $=\sim 578-9$ at $8 \mathrm{~min}$ ) (Figure 3A) and a red shift of di-4-ANEPPS fluorescence (control EM: $575 \mathrm{~nm}$; AMD treated EM: $580 \mathrm{~nm}$ ) (Figure 3B) indicating membrane hyperpolarization according to studies on S. cerevisiae by other researchers [41,51].

A

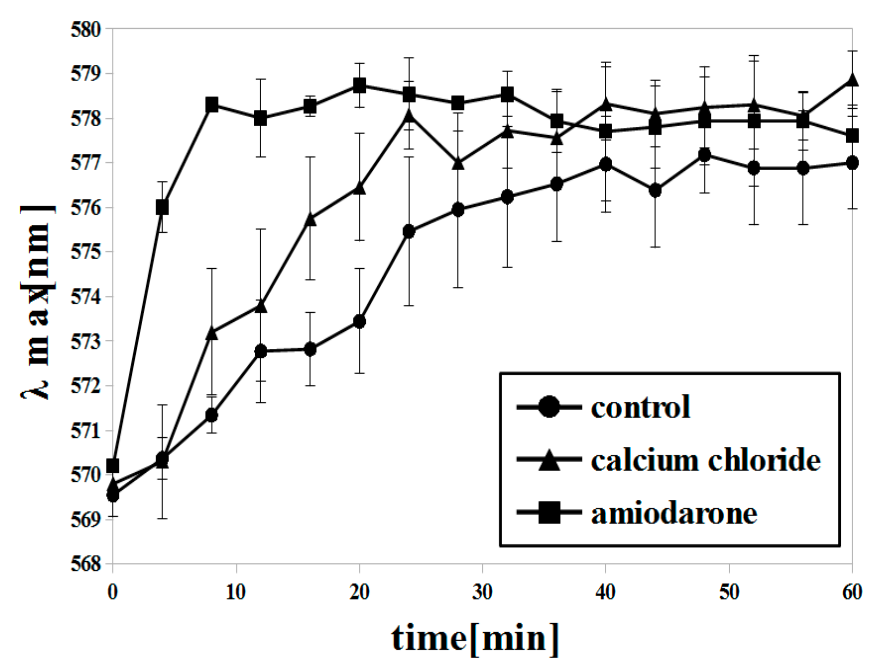

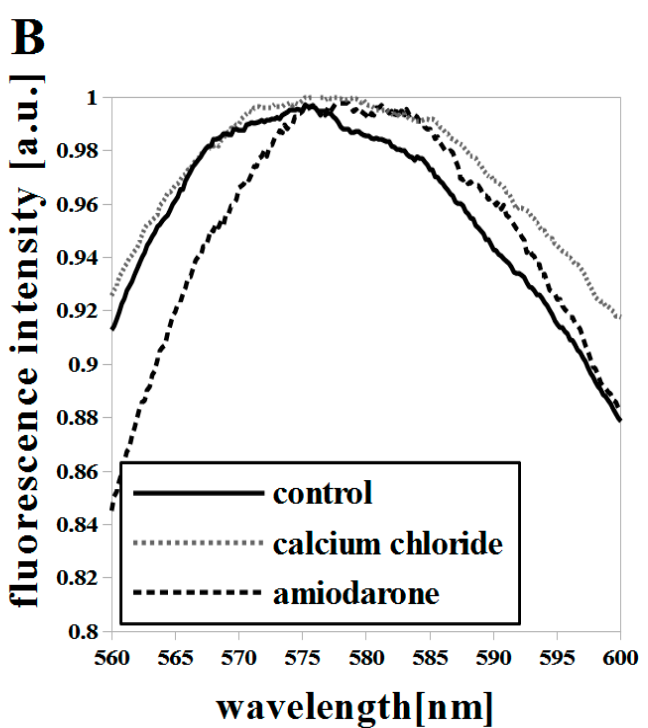

Figure 3. $\Delta \psi$ increase and membrane hyperpolarization in $C$. albicans induced with calcium chloride $\left(\mathrm{CaCl}_{2}\right)(25 \mathrm{mM})$ and amiodarone (AMD) $(2 \mu \mathrm{M})$ in early log phase $(8 \mathrm{~h})$ shown by: (A) diS- $\mathrm{C}_{3}(3)$, means \pm SD $(n=4)$ and $(B)$ di-4-ANEPPS $(R-B$ values $=0.978 \pm 0.011,0.996 \pm 0.006$ and $1.033 \pm 0.023$ for control, $\mathrm{CaCl}_{2}, \mathrm{AMD}$, respectively), each spectrum is averaged $(\mathrm{n}=9)$. 


\subsection{Di-4-ANEPPS Is a Suitable Tool for Fast Measuring of the Influence of Detergents on $\Delta \psi$}

In Figures $1-3$ we show the validation of the usage of di-4-ANEPPS in $\Delta \psi$ measurements in comparison to already known diS- $C_{3}(3)$ dye. The di-4-ANEPPS assay is more rapid and reliable due to lack of toxicity towards C. albicans cells (Figure 1D) and unlike diS- $C_{3}(3)$, the di-4-ANEPPS $\Delta \psi$ measurements are not interfered with by $\mathrm{ABC}$ transporters activity (Figure 1E). Here, we wanted to show the vast potential of the di-4-ANEPPS dye for rapid screening of $\Delta \psi$ in C. albicans as a result of cell physiology changes. We selected the influence of amphipathic compounds on C. albicans' membranes using three detergents: cationic benzalkonium chloride (BAC), anionic sodium dodecyl sulfate (SDS) and non-ionic Triton X-100. Additionally, for more clear presentation of di-4-ANEPPS fluorescence shifts we used an R-B ratio formula, described in Section 2.5.

The mechanism of antifungal action of commonly used detergents is often not well understood. Kodedova et al. [53] showed that detergents at high concentrations cause membrane permeabilization in S. cerevisiae and outflow of cations from the inside of the cell. Permeabilized cells cannot maintain $\Delta \psi$ and there is a massive outflow of cations from the inside of the cell. Gaskova et al. [37] noted that this outflow of cations enhances diS- $\mathrm{C}_{3}(3)$ binding capacity of the cytosolic components and this leads to a fast increase of $\lambda$ max.

SDS is an efficient solubilizer of integral membrane proteins [54]. At low concentrations, SDS increased the permeability of the $S$. cerevisiae plasma membrane, as demonstrated by Kodedova et al. [53], using diS- $\mathrm{C}_{3}(3)$, whereas at a higher concentration $(1.44 \mathrm{mg} / \mathrm{mL})$, SDS caused a very rapid red shift of diS- $\mathrm{C}_{3}(3)$ indicating fully permeabilized membranes. The intensity of antifungal activity of SDS depends on the time of incubation with cells and the concentration used. After a 30 min treatment with SDS, we observed hyperpolarization of the plasma membrane in a range of $80-320 \mu \mathrm{g} / \mathrm{mL}$ SDS (R-B ratio increase of up to $\sim 1.15$ at $320 \mu \mathrm{g} / \mathrm{mL}$ ) (Figure 4). PI measurements indicate a $25 \%$ permeabilization at a concentration of $80 \mu \mathrm{g} / \mathrm{mL} \mathrm{SDS}$ and fully permeabilized cells in higher concentrations (Figure 5).

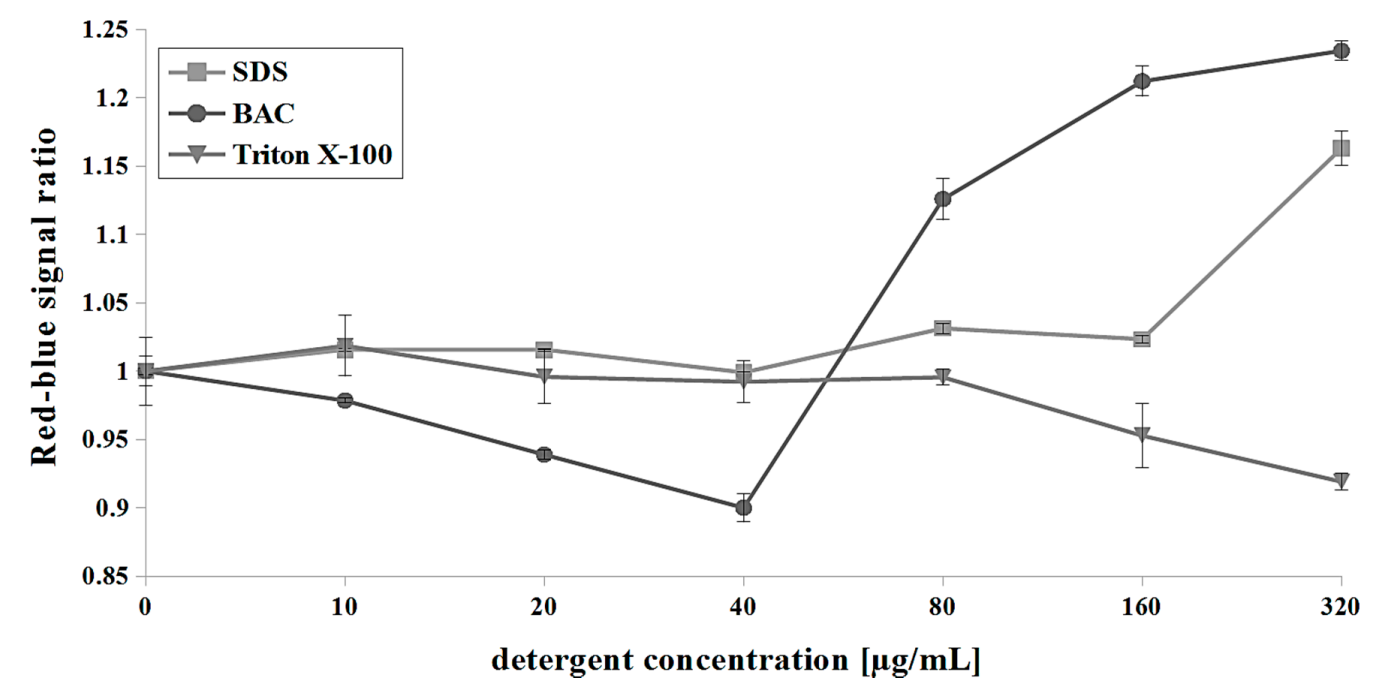

Figure 4. The influence of detergents sodium dodecyl sulfate (SDS) (0-320 $\mu \mathrm{g} / \mathrm{mL})$, benzalkonium chloride (BAC) $(0-320 \mu \mathrm{g} / \mathrm{mL})$ and Triton X-100 $(0-320 \mu \mathrm{g} / \mathrm{mL})$ on $\Delta \psi$. For data analysis, red-blue signal ratio (R-B ratio) was calculated as described in Section 2.5, means $\pm \operatorname{SD}(n=9)$.

BAC is a quaternary ammonium compound which has been used in clinical applications since 1935 [55]. Kodedova et al. [53] found that $18 \mu \mathrm{g} / \mathrm{mL}$ BAC caused a red shift in S. cerevisiae cells stained with diS- $\mathrm{C}_{3}(3)$, which indicated partial permeabilization of cells while others have been depolarized. At $0.36 \mu \mathrm{g} / \mathrm{mL}$ BAC the cells were depolarized [53]. Our results with di-4-ANEPPS show a similar trend in BAC interaction with C. albicans cells. We observed depolarization of cells in the range of $10-40 \mu \mathrm{g} / \mathrm{mL}$ BAC (R-B ratio drop of up to 0.9 at $40 \mu \mathrm{g} / \mathrm{mL}$ ) and hyperpolarization when the concentrations of 
80-320 $\mu \mathrm{g} / \mathrm{mL}$ BAC were used (R-B ratio increase of up to $\sim 1.25$ at $320 \mu \mathrm{g} / \mathrm{mL}$ ) (Figure 4). As we show in Figure 5, BAC induced the highest permeability of membranes among the used detergents in the concentration of $20 \mu \mathrm{g} / \mathrm{mL}$ ( $>90 \%$ permeabilized cells) and from a concentration of $40 \mu \mathrm{g} / \mathrm{mL}$ we observed a full permeabilization of cells.

\section{A concentration $[\mu \mathrm{g} / \mathrm{mL}]$}
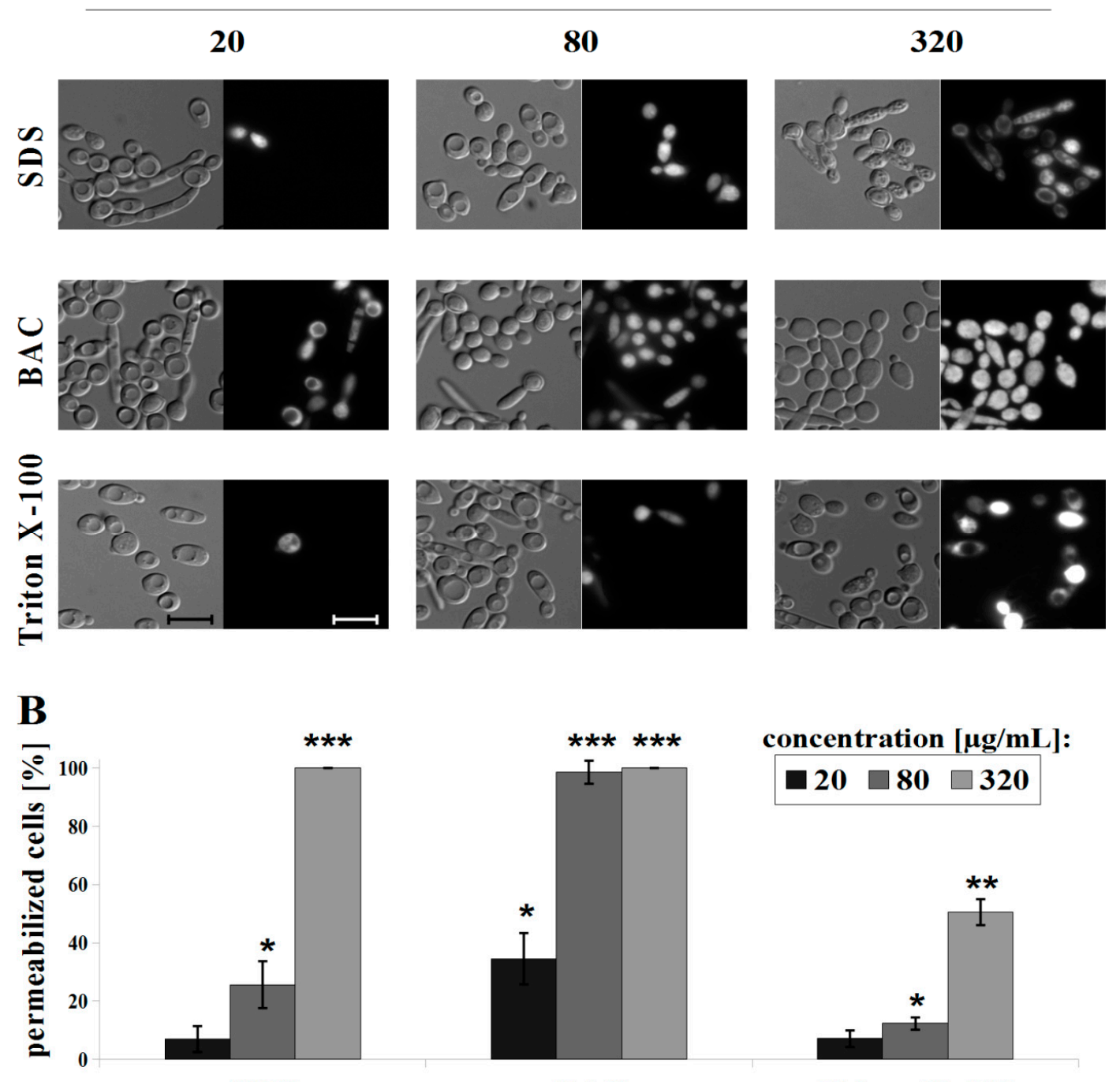

SDS

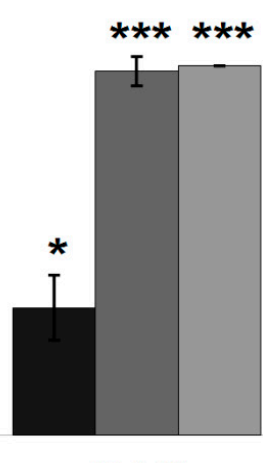

BAC
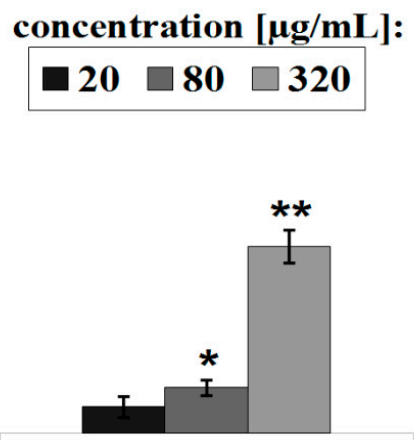

Triton X-100

Figure 5. C. albicans CAF2-1 strain staining with propidium iodide (PI) after treatment with detergents: SDS, BAC and Triton X-100, presented as: (A) microscopic observations, scale bar $=10 \mu \mathrm{m}$ and (B) histograms of the counted \% of permeabilized cells, means \pm SD $(n=3)$, statistical analysis at each concentration was performed relative to control experiment without detergent $\left({ }^{*} p<0.05 ;{ }^{* *} p<0.01\right.$; $* * * 00.001)$.

The nonionic detergent Triton X-100 was previously used for permeabilization as a tool for the assay of yeast intracellular enzymes in whole cells [56], but the information on the Triton X-100 effect of yeast plasma membrane is scarce. Using di-4-ANEPPS and PI, we observed the weakest effect of Triton X-100 among the detergents used. Triton X-100 induced a blue shift of di-4-ANEPPS (R-B = 0.95 and 0.9 at 160 and $320 \mu \mathrm{g} / \mathrm{mL}$, respectively), which means depolarization of the C. albicans plasma membrane only at the highest concentrations used (Figure 4). We also observed approximately 50\% permeabilization of C. albicans cells at $320 \mu \mathrm{g} / \mathrm{mL}$ Triton X-100 (Figure 5). 


\section{Conclusions}

In this study, we reported the use of di-4-ANEPPS dye on $\Delta \psi$ measurements of $C$. albicans. For the development of the method, we tested different conditions disturbing ion homeostasis, such as cell aging or de- and hyperpolarising agents ( $\mathrm{KCl}$ and $\mathrm{DM}-11 ; \mathrm{CaCl}_{2}$ and $\mathrm{AMD}$ ) and compared results with the known diS- $C_{3}(3)$ assay. We provided new information on the response of $C$. albicans under those conditions and discussed our data based on the findings reported by other research groups using non-pathogenic $S$. cerevisiae. Due to the advantages of di-4-ANEPPS over diS- $C_{3}(3)$, we developed an R-B ratio formula for rapid $\Delta \psi$ calculations and proposed it as a method for detection of $C$. albicans physiology disturbances on the example of the influence of commonly used detergents (SDS, BAC and Triton X-100).

Author Contributions: J.S.; conception, design, analysis, and interpretation of data for the work, preparation of the figures. A.K.; conception, interpretation of data for the work, writing and editing the manuscript.

Funding: This work was supported by the National Science Centre, Poland, NCN Grants: 2016/23/B/NZ1/01928, 2017/25/N/NZ1/00050 and by Wrocław Centre of Biotechnology, Program: the Leading National Research Centre (KNOW) for 2014-2018.

Conflicts of Interest: The authors declare no conflict of interest.

\section{References}

1. Gásková, D.; Brodská, B.; Herman, P.; Vecer, J.; Malínský, J.; Sigler, K.; Benada, O.; Plásek, J. Fluorescent probing of membrane potential in walled cells: diS-C3(3) assay in Saccharomyces cerevisiae. Yeast 2007, 14, 1189-1197. [CrossRef]

2. Leonard, R.J.; Garcia, M.L.; Slaughter, R.S.; Reuben, J.P. Selective blockers of voltage-gated K+ channels depolarize human T lymphocytes: mechanism of the antiproliferative effect of charybdotoxin. Proc. Nat. Acad. Sci. USA 1992, 89, 10094-10098. [CrossRef]

3. Grossmann, G.; Opekarová, M.; Malinsky, J.; Weig-Meckl, I.; Tanner, W. Membrane potential governs lateral segregation of plasma membrane proteins and lipids in yeast. EMBO J. 2007, 26, 1-8. [CrossRef] [PubMed]

4. Kett, D.H.; Azoulay, E.; Echeverria, P.M.; Vincent, J.L. Candida bloodstream infections in intensive care units: Analysis of the extended prevalence of infection in intensive care unit study. Crit. Care Med. 2011, 39, 665-670. [CrossRef] [PubMed]

5. Vacata, V.; Kotyk, A.; Sigler, K. Membrane potentials in yeast cells measured by direct and indirect methods. Biochim. Biophys. Acta 1981, 643, 265-268. [CrossRef]

6. Prasad, R.; Hofer, M. Tetraphenylphosphonium is an indicator of negative membrane potential in Candida albicans. Biochim. Biophys. Acta 1986, 861,377-380. [CrossRef]

7. Sanglard, D.; Ischer, F.; Parkinson, T.; Falconer, D.; Bille, J. Candida albicans mutations in the ergosterol biosynthetic pathway and resistance to several antifungal agents. Antimicrob. Agents Chemother. 2003, 47, 2404-2412. [CrossRef] [PubMed]

8. Suchodolski, J.; Feder-Kubis, J.; Krasowska, A. Antifungal activity of ionic liquids based on (-)-menthol: A mechanism study. Microbiol. Res. 2017, 197, 56-64. [CrossRef]

9. Thevelein, J.M.; Beullens, M.; Honshoven, F.; Hoebeeck, G.; Detremerie, K.; Den Hollander, J.A.; Jans, A.W.H. Regulation of the cAMP level in the yeast Saccharomyces cerevisiae: Intracellular $\mathrm{pH}$ and the effect of membrane depolarizing compounds. J. Gen. Microbiol. 1987, 133, 2191-2196. [CrossRef]

10. Liao, R.S.; Rennie, R.P.; Talbot, J.A. Assessment of the effect of amphotericin B on the vitality of Candida albicans. Antimicrob. Agents Chemother. 1999, 43, 1034-1041. [CrossRef]

11. Hwang, B.; Hwang, J.S.; Lee, J.; Lee, D.G. The antimicrobial peptide, psacotheasin induces reactive oxygen species and triggers apoptosis in Candida albicans. Biochem. Biophys. Res. Commun. 2011, 405, 267-271. [CrossRef]

12. Epps, D.E.; Wolfe, M.L.; Groppi, V. Characterization of the steady-state and dynamic fluorescence properties of the potential-sensitive dye bis-(1,3-dibutylbarbituric acid) trimethine oxonol (DiBAC4(3)) in model systems and cells. Chem. Phys. Lipids 1994, 69, 137-150. [CrossRef]

13. Cabrini, G.; Verkman, A.S. Potential-sensitive response mechanism of diS-C3-(5) in biological membranes. J. Membr. Biol. 1986, 92, 171-182. [CrossRef] 
14. Novo, D.; Perlmutter, N.G.; Hunt, R.H.; Shapiro, H.M. Accurate flow cytometric membrane potential measurement in bacteria using diethyloxacarbocyanine and a ratiometric technique. Cytometry 1999, 35, 55-63. [CrossRef]

15. Szczepaniak, J.; Łukaszewicz, M.; Krasowska, A. Detection of inhibitors of Candida albicans Cdr transporters using a diS-C3(3) fluorescence. Front. Microbiol. 2015, 6, 176. [CrossRef]

16. Čadek, R.; Chládková, K.; Sigler, K.; Gášková, D. Impact of the growth phase on the activity of multidrug resistance pumps and membrane potential of $S$. cerevisiae: Effect of pump overproduction and carbon source. BBA Biomembr. 2004, 1665, 111-117. [CrossRef]

17. Schaffer, P.; Ahammer, H.; Müller, W.; Koidl, B.; Windisch, H. Di-4-ANEPPS causes photodynamic damage to isolated cardiomyocytes. Pflug. Arch. Eur. J. Phys. 1994, 426, 548-551. [CrossRef]

18. Fromherz, P.; Müller, C.O. Voltage-sensitive fluorescence of amphiphilic hemicyanine dyes in neuron membrane. Biochim. Biophys. Acta 1993, 1150, 111-122. [CrossRef]

19. Gross, E.; Bedlack, R.S.; Loew, L.M. Dual-wavelength ratiometric fluorescence measurement of the membrane dipole potential. Biophys. J. 1994, 67, 208-216. [CrossRef]

20. Montana, V.; Farkas, D.L.; Loew, L.M. Dual-wavelength ratiometric fluorescence measurements of membrane potential. Biochemistry 1989, 28, 4536-4539. [CrossRef]

21. McGahren, E.D.; Beach, J.M.; Duling, B.R. Capillaries demonstrate changes in membrane potential in response to pharmacological stimuli. Am. J. Physiol. 1998, 274, 60-65. [CrossRef]

22. Beach, J.M.; McGahren, E.D.; Xia, J.; Duling, B.R. Ratiometric measurement of endothelial depolarization in arterioles with a potential-sensitive dye. Am. J. Physiol. 1996, 270, 2216-2227. [CrossRef] [PubMed]

23. Kao, W.Y.; Davis, C.E.; Kim, Y.I.; Beach, J.M. Fluorescence emission spectral shift measurements of membrane potential in single cells. Biophys. J. 2001, 81, 1163-1170. [CrossRef]

24. Chaloupka, R.; Plášek, J.; Slavík, J.; Siglerová, V.; Sigler, K. Measurement of membrane potential in Saccharomyces cerevisio by the electrochromic probe di-4-ANEPPS: Effect of intracellular probe distribution. Folia Microbiol. 1997, 42, 451-456. [CrossRef]

25. Fonzi, W.A.; Irwin, M.Y. Isogenic strain construction and gene mapping in Candida albicans. Genetics 1993, 134, 717-728. [PubMed]

26. Szczepaniak, J.; Łukaszewicz, M.; Krasowska, A. Estimation of Candida albicans ABC transporter behavior in real-time via fluorescence. Front. Microbiol. 2015, 6, 1382. [CrossRef]

27. Saccharomyces Genome Database. Available online: https://www.yeastgenome.org/locus/S000003629 (accessed on 2 March 2019).

28. Candida Genome Database. Available online: http://www.candidagenome.org/cgi-bin/locus.pl?locus=C4 00670W_A\&organism=C_albicans_SC5314 (accessed on 2 March 2019).

29. EMBOSS Needle. Available online: https://www.ebi.ac.uk/Tools/psa/emboss_needle/nucleotide.html (accessed on 2 March 2019).

30. Bachtel, A.D.; Gray, R.A.; Stohlman, J.M.; Bourgeois, E.B.; Pollard, A.E.; Rogers, J.M. A novel approach to dual excitation ratiometric optical mapping of cardiac action potentials with di-4-ANEPPS using pulsed LED excitation. IEEE Trans. BioMed. Eng. 2011, 58, 2120-2126. [CrossRef]

31. Rodaki, A.; Bohovych, I.M.; Enjalbert, B.; Young, T.; Odds, F.O.; Gow, N.A.R.; Brown, A.J.P. Glucose promotes stress resistance in the fungal pathogen Candida albicans. Mol. Biol. Cell 2009, 20, 4845-4855. [CrossRef]

32. Calahorra, M.; Sanchez, N.S.; Pena, A. Characterization of glycolytic metabolism and ion transport of Candida albicans. Yeast 2012, 29, 357-370. [CrossRef]

33. Nso, E.; Goffeau, A.; Dufour, J.P. Fluctuations during growth of the plasma membrane H(+)-ATPase activity of Saccharomyces cerevisiae and Schizosaccharomyces pombe. Folia Microbiol. 2002, 47, 401-406. [CrossRef]

34. Tsutsui, H.; Jinno, Y.; Tomita, A.; Okamura, Y. Rapid evaluation of a protein-based voltage probe using a field-induced membrane potential change. BBA Biomembr. 2014, 1838, 1730-1737. [CrossRef]

35. Miranda, M.; Bashi, E.; Vylkova, S.; Edgerton, M.; Slayman, C.; Rivetta, A. Conservation and dispersion of sequence and function in fungal TRK potassium transporters: Focus on Candida albicans. FEMS Yeast Res. 2009, 9, 278-292. [CrossRef]

36. Hušeková, B.; Elicharová, H.; Sychrová, H. Pathogenic Candida species differ in the ability to grow at limiting potassium concentrations. Can. J. Microbiol. 2016, 62, 394-401. [CrossRef] 
37. Gaskova, D.; Cadek, R.; Chaloupka, R.; Plasek, J.; Sigler, K. Factors underlying membrane potential-dependent and -independent fluorescence responses of potentiometric dyes in stressed cells: diS-C3(3) in yeast. Biochim. Biophys. Acta 2001, 1511, 74-79. [CrossRef]

38. Ariño, J.; Ramos, J.; Sychrová, H. Alkali metal cation transport and homeostasis in yeasts. Microbiol. Mol. Biol. Rev. 2010, 74, 95-120. [CrossRef]

39. Bertl, A.; Bilher, H.; Reid, J.D.; Kettner, C.; Slayman, C.I. Physiological characterization of the yeast plasma membrane outward rectifying K+ channel, DIK1 (TOK1) in situ. J. Membr. Biol. 1998, 162, 67-80. [CrossRef]

40. Maresova, J.; Urbankova, E.; Gaskova, D.; Sychrova, H. Measurements of plasma membrane potential changes in Saccharomyces cerevisiae cells reveal the importance of the Tok1 channel in membrane potential maintenance. FEMS Yeast Res. 2006, 6, 1039-1046. [CrossRef]

41. Maresova, L.; Muend, S.; Zhang, Y.Q.; Sychrova, H.; Rao, R. Membrane hyperpolarization drives cation influx and fungicidal activity of amiodarone. J. Biol. Chem. 2009, 284, 2795-2802. [CrossRef]

42. Hendrych, T.; Kodedova, M.; Sigler, K.; Gaskova, D. Characterization of the kinetics and mechanisms of inhibition of drugs interacting with the S. cerevisiae multidrug resistance pumps Pdr5p and Snq2p. Biochim. Biophys. Acta 2009, 1788, 717-723. [CrossRef]

43. Lachowicz, T.M.; Krasowska, A.; Łuczyński, J.; Witek, S. Plasma membrane H+ATPase activity in wild type and mutants of yeast Saccharomyces cerevisiae treated by some lysosomotropic drugs. Folia Microbiol. 1998, 43, 203-205. [CrossRef]

44. Krasowska, A.; Chmielewska, L.; Łuczyński, J.; Witek, S.; Sigler, K. Dual mechanism of the antifungal effect of new lysosomotropic agents on Saccharomyces cerevisiae RXII strain. Cell. Mol. Biol. Lett. 2003, 8, 111-120.

45. Zahumenský, J.; Jančíková, I.; Drietomská, A.; Švenkrtová, A.; Hlaváček, O.; Hendrych, T.; Plášek, J.; Sigler, K.; Gášková, D. Yeast Tok1p channel is a major contributor to membrane potential maintenance under chemical stress. BBA Biomembr. 2017, 1859, 1974-1985. [CrossRef]

46. Paidhungat, M.; Garrett, S. A homolog of mammalian, voltage-gated calcium channels mediates yeast pheromone-stimulated Ca2+ uptake and exacerbates the cdc1(Ts) growth defect. Mol. Cell. Biol. 1997, 17, 6339-6347. [CrossRef]

47. Iida, H.; Nakamura, H.; Ono, T.; Okumura, M.; Anraku, Y. MID1, a novel Saccharomyces cerevisiae gene encoding a plasma membrane protein, is required for Ca2+ influx and mating. Mol. Cell. Biol. 1994, 14, 8259-8271. [CrossRef]

48. Muller, E.M.; Mackin, N.A.; Erdman, S.E.; Cunningham, K.W. Fig1p facilitates Ca2+ influx and cell fusion during mating of Saccharomyces cerevisiae. J. Biol. Chem. 2003, 278, 38461-38469. [CrossRef]

49. Brand, A.; Shanks, S.; Duncan, V.M.S.; Yang, M.; Mackenzie, K.; Gow, N.A.R. Hyphal orientation of Candida albicans is regulated by a calcium-dependent mechanism. Curr. Biol. 2007, 17, 347-352. [CrossRef]

50. Muller, E.M.; Locke, E.G.; Cunningham, K.W. Differential regulation of two Ca2+ influx systems by pheromone signaling in Saccharomyces cerevisiae. Genetics 2001, 159, 1527-1538.

51. Pena, A.; Calahorra, M.; Michel, B.; Ramirez, J.; Sanchez, N.S. Effects of amiodarone on K+, internal pH and Ca2+ homeostasis in Saccharomyces cerevisiae. FEMS Yeast Res. 2009, 9, 832-848.

52. Calahorra, M.; Sanchez, N.S.; Peña, A. Effects of acridine derivatives on Ca2+ uptake by Candida albicans. Bioenergetics 2017, 6, 152. [CrossRef]

53. Kodedova, M.; Sigler, K.; Lemire, B.D.; Gaskova, D. Fluorescence method for determining the mechanism and speed of action of surface-active drugs on yeast cells. Biotechniques 2011, 50, 58-63. [CrossRef]

54. Maite, M.; Champeil, P.; Moller, J.V. Interaction of membrane proteins and lipids with solubilizing detergents. Biochim. Biophys. Acta 2000, 1508, 86-111.

55. Block, S.S. Disinfection, Sterilization and Preservation, 4th ed.; Lea \& Febiger: Philadelphia, PA, USA, 1991.

56. Laouar, L.; Muligan, B.J.; Lowe, K.C. Yeast permeabilization with surfactants. Biotechnol. Lett. 1992, 14, 719-720. [CrossRef]

(C) 2019 by the authors. Licensee MDPI, Basel, Switzerland. This article is an open access article distributed under the terms and conditions of the Creative Commons Attribution (CC BY) license (http://creativecommons.org/licenses/by/4.0/). 